\title{
Effect of nusinersen on respiratory function in paediatric spinal muscular atrophy types 1-3
}

\author{
Archana Chacko, ${ }^{1,2}$ Peter D Sly (1) , ${ }^{1}$ Robert S Ware, ${ }^{3}$ Nelufa Begum, ${ }^{1}$ Sean Deegan, ${ }^{2}$ \\ Nicole Thomas, ${ }^{4}$ Leanne M Gauld (i) ${ }^{2}$
}

\begin{abstract}
- Additional supplemental material is published online only. To view, please visit the journal online (http://dx.doi. org/10.1136/thoraxjnl-2020 216564)
\end{abstract}

${ }^{1}$ Centre for Children's Research, The University of Queensland, South Brisbane, Queensland, Australia

${ }^{2}$ Respiratory and Sleep Medicine, Children's Health Queensland Hospital and Health Service, South Brisbane, Queensland, Australia ${ }^{3}$ Menzies Health Institute, Griffith University, Brisbane, Queensland, Australia ${ }^{4}$ Neuromuscular Physiotherapy Department, Queensland Children's Hospital, South Brisbane, Queensland, Australia

\section{Correspondence to}

Dr Archana Chacko, The University of Queensland Child Health Research Centre, Brisbane, QLD 4072, Australia; archana.bodapati@hotmail.com

Received 12 November 2020 Revised 17 March 2021 Accepted 29 March 2021 Published Online First 7 May 2021

\section{ABSTRACT}

Introduction Nusinersen is used in spinal muscular atrophy (SMA) to improve peripheral muscle function; however, respiratory effects are largely unknown.

Aim To assess the effects of nusinersen on respiratory function in paediatric SMA during first year of treatment. Methods A prospective observational study in paediatric patients with SMA who began receiving nusinersen in Queensland, Australia, from June 2018 to December 2019. Outcomes assessed were the age-appropriate respiratory investigations: spirometry, oscillometry, sniff nasal inspiratory pressure, mean inspiratory pressure, mean expiratory pressure, lung clearance index, as well as polysomnography (PSG) and muscle function testing. Lung function was collected retrospectively for up to 2 years prior to nusinersen initiation. Change in lung function was assessed using mixed effects linear regression models, while PSG and muscle function were compared using the Wilcoxon signed-rank test.

Results Twenty-eight patients (15 male, aged 0.0818.58 years) were enrolled: type $1(n=7)$; type $2(n=12)$; type $3(n=9)$. The annual rate of decline in FVC z-score prior to nusinersen initiation was $-0.58(95 \% \mathrm{Cl}-0.75$ to -0.41$)$, and post initiation was $-0.25(95 \% \mathrm{Cl}-0.46$ to -0.03$)$, with a significant difference in rate of decline (0.33 (95\% Cl 0.02 to 0.66$)(p=0.04))$. Most lung function measures were largely unchanged in the year post nusinersen initiation. The total Apnoea-Hypopnoea Index (AHI) was reduced from a median of 5.5 events/ hour (IQR 2.1-10.1) at initiation to 2.7 events/hour (IQR $0.7-5.3)$ after 1 year $(p=0.02)$. All SMA type $1 \%$ and $75 \%$ of SMA types 2 and 3 had pre-defined peripheral muscle response to nusinersen.

Conclusion The first year of nusinersen treatment saw reduced lung function decline (especially in type 2) and improvement in $\mathrm{AHI}$.

\section{INTRODUCTION}

Spinal muscular atrophy (SMA) is an autosomal recessive disease caused by deletion or mutation of the SMN1 gene which reduces full-length survival motor neuron (FL SMN) protein levels. The survival motor neuron 2 (SMN2) gene produces FL SMN protein but more if it is in its truncated, non-functional isoform. Increased SMN2 copy numbers produce more functional FL SMN protein, leading to reduced disease severity; thus, the SMN2 gene has been the principal target for therapies. ${ }^{1}$ Nusinersen is an antisense oligonucleotide that alters SMN2 splicing to favour expression of stable FL SMN protein. ${ }^{2}$

\section{Key messages}

What is the key question?

- Nusinersen improves peripheral motor function in children with spinal muscular atrophy, but does it also improve respiratory muscle function?

What is the bottom line?

- Nusinersen reduces the decline in lung function seen prior to treatment in paediatric spinal muscular atrophy and improves sleepdisordered breathing.

Why read on?

- Spinal muscular atrophy (SMA), especially SMA type 1, is no longer a palliative condition, and although not curative, nusinersen is now widely used to treat these children and pulmonary physicians should be aware of the real-world changes in respiratory function seen with treatment.

Reduction in SMN protein levels leads to spinal anterior horn cell atrophy and subsequent lower motor neuron weakness. ${ }^{1}$ SMA is classified into SMA types $0-4$ depending on age of onset and the maximal motor milestone achieved. SMA type 0-3 comprise the paediatric forms: type 0 is lethal in the neonatal period; type 1 being the most severe infant form (survival $<2$ years old); survival into adolescence and adulthood is increasingly common with SMA type 2 with two thirds living through their mid-twenties and survival for type 3 is normal. SMA type 4 comprises of minor weakness in early adulthood. The cause of mortality in the severe phenotypes is predominantly due to respiratory complications.

However, the SMA disease phenotype and prognosis appears to be improving with disease-modifying medications. Nusinersen has documented short-term efficacy in SMA, improving peripheral muscle function (Nusinersen Versus Sham Control in InfantileOnset SMA (ENDEAR trial); Nusinersen Versus Sham Control in Later-Onset SMA (CHERISH trial)).$^{45}$ Event-free and overall survival improved in infants; effects on survival in older children are unknown (as there were no deaths in the CHERISH trial). ${ }^{46}$ Greater benefits were seen in those treated early (with shorter disease duration). ${ }^{5}$ Although there are limited longer term follow-up studies, early evidence suggests that initial improvements are maintained. ${ }^{78}$ Nusinersen 
may reduce respiratory impairment, with improved survival and reduced need for respiratory support in infants. However, this has not been well characterised. Nusinersen treatment is demanding (regular intrathecal administration) and expensive, and longterm efficacy or respiratory outcomes are yet to be evaluated. As respiratory complications are the leading cause of morbidity and mortality, ${ }^{9-11}$ it is imperative that treatment effects on respiratory function are characterised.

The aim of the present study was to assess the effect of nusinersen on respiratory function in a real-world population of children with SMA.

\section{METHODS}

\section{Study design and patients}

A prospective, observational study of all children with SMA types 1-3 starting treatment with nusinersen at the Queensland Children's Hospital Brisbane (QCH), Australia, was conducted between June 2018 and December 2019. Catchment for this tertiary hospital includes all children in Queensland and northern New South Wales (population $\sim 5$ million). At enrolment, children had/were

1. Under 19 years of age.

2. Genetically confirmed homozygous SMN1 gene alteration.

3. Clinical features of SMA.

4. Receiving specialist care at QCH.

5. Nusinersen naïve.

Children were not excluded if they required either invasive or non-invasive ventilation (NIV), or unable to perform lung function.

Study exclusion criteria are as follows:

1. Lack of consent/assent.

2. Unwell or unable to receive doses of nusinersen within reasonable proximity to scheduled dosing.

The parents of all children gave written informed consent. Research was funded by Biogen Global as an investigator-initiated project.

\section{Clinical assessment}

Retrospective review of medical records was undertaken for each participant recording demographic data, clinical deterioration events, including lower respiratory tract infections or initiation of NIV in the 2 years prior to nusinersen initiation. All pulmonary function tests (PFTs) performed in the 2 years prior to nusinersen initiation were extracted. Usual clinical management continued throughout the study period with admissions, NIV initiation, surgery and survival noted prospectively during the 12-month follow-up period.

Children underwent peripheral muscle function assessments and lung function tests, timed to nusinersen dosing schedule (see table 1).

\section{Study objectives}

The primary objective is as follows:

1. To assess the effect of nusinersen on respiratory function (with lung function testing and PSG) in children with type 1, 2 and 3 SMA starting on nusinersen.

The secondary objectives are as follows:
1. To establish if there was a relationship between respiratory muscle function and peripheral muscle function.

2. To establish if there was a respiratory muscle function response in peripheral muscle function non-responders.

3. To establish if there was an effect in children with SMA type 3 , where the clinical evidence for treatment is limited.

\section{Pulmonary function tests}

A qualified paediatric respiratory scientist conducted PFT according to the American Thoracic Society and European Respiratory Society Technical Statement. ${ }^{12}$ Multiple modalities were used to evaluate respiratory function, depending on age and cooperation of the child. Tests included spirometry for FVC, oscillometry (Osc) (respiratory reactance at $8 \mathrm{~Hz}(\mathrm{Xrs} 8)$, respiratory resistance at $8 \mathrm{~Hz}(\mathrm{Rrs} 8)$ ), peak cough flow (PCF), sniff nasal inspiratory pressure (SNIP), mean inspiratory pressure (MIP)/mean expiratory pressure (MEP) and multiple breath washout (lung clearance index (LCI), functional residual capacity (FRC)). Raw scores, percent predicted or z-scores were reported. Both measures of lung function are reported to allow comparison with previous literature.

See online supplemental 1 for details on testing procedures.

\section{Polysomnography}

Children underwent level 1 diagnostic PSG. Those treated with NIV had a diagnostic component (priori duration set—study start to end of two rapid eye movement (REM) stage sleep cycles) with NIV removed during PSG (split study). Only diagnostic component was used for analysis and for determining the relationships with lung function and peripheral muscle function. PSG was performed in QCH paediatric sleep laboratory using EMBLA (N7000, Natus Neuro, Middleton, Wisconsin, USA) equipment and attended by trained paediatric sleep nurses (see online supplemental 1 for details on the PSG set-up). For study purposes, two experienced paediatric sleep physicians scored each PSG from raw data independently. The PSG was scored using the American Academy of Sleep Medicine (AASM) V.2.6 (see further details in online supplemental 1) paediatric criteria. $^{13}$

PSG was evaluated for sleep-disordered breathing (SDB), obstructive (OSA), central (CSA) and mixed sleep apnoea and hypoventilation. To avoid misclassification, an obstructive hypopnea was scored if they met the AASM 2020 criteria for an obstructive hypopnoea and the following were also present in the setting of muscle weakness ${ }^{14}$ :

- Increasing phase difference between chest and abdominal movements; or

- Stable/increasing submental EMG (particularly at end of the event); or

- Phasic diaphragmatic EMG activity.

\section{Peripheral muscle function}

Qualified paediatric neuromuscular physiotherapists tested peripheral muscle function using tests validated in $\mathrm{SMA}^{15-18}$ : the Children's Hospital of Philadelphia Infant Test of Neuromuscular Disorders (CHOP INTEND (type 1) ${ }^{16}$; Hammersmith Functional

\begin{tabular}{llllllll}
\hline \multicolumn{2}{l}{ Table 1} & Study testing schedule & & & & & \\
\hline Study day & Baseline & Day 15 & Day 29 & Day 64 & Day 183 & Day 302 & Day 365 \\
\hline Nusinersen dose & Dose 1 & Dose 2 & Dose 3 & Dose 4 & Dose 5 & Dose 6 & No dose \\
Tests completed & PFT & & PFT & PFT & PFT & PFT & PFT \\
& PSG & & & & & Muscle function testing & Muscle function testing \\
\hline
\end{tabular}

PFT, pulmonary function test; PSG, polysomnography. 
Motor Scale-Expanded (HFMSE (types 2 and 3)) ${ }^{17}$ or Revised Upper Limb Module (RULM) for SMA (types 2 and 3$)^{18}$ were used at discretion of the physiotherapist depending on baseline peripheral muscle function (see online supplemental 1 for details on muscle function test scoring). Definition used for motor response was adopted from CHERISH and ENDEAR trials ${ }^{45}$ :

- CHOP INTEND score increase of at least four points from baseline.

- HFMSE score increase of at least three points from baseline.

- Any increase in RULM from baseline.

Sample size

OSc values were used for priori sample size justification, as many children are too young to perform spirometry. In a previously published case series involving 12 children with SMA type 2 who were followed up for a 12-month period, the mean rate of change of Rsr8 was 0.51 z-scores per year, with $\mathrm{SD}=0.83 .{ }^{19}$ To reject the null hypothesis that there is no change over the 12-month study period, assuming alpha $=0.05$ and the mean (SD) change $=0.51$ (0.83) z-scores, then 12-month follow-up data were required on 14 participants.

\section{Statistical analysis}

Descriptive statistics for continuous data are reported as either mean (SD), median (IQR) or median (range) as appropriate, or as frequency (percentage (\%)) for categorical data. The primary outcome, change in FVC z-score, was assessed using a linear spline with a knot at day 0 of treatment. Linear splines assume the change in FVC $\mathrm{z}$-score is constant in the 2 years prior to treatment initiation, and, separately, constant in the 1 year post initiation, and that the two linear segments are constrained to have the same value at the knot. The model was calculated using mixed effects to account for the repeated measures on some children; time since initiation was entered as the fixed effect and participant was entered as the random effect. Results are reported as mean difference (MD) and 95\% CI. Assumptions underlying linear regression models were tested and confirmed.

To test the difference in lung function and AHI total score for muscle responder and non-responder group and to test the difference in sleep events by SMA type between treatment initiation and 12-month follow-up, we used Mann-Whitney test.

Bland-Altman agreement methods were used to assess agreement between sleep events scoring from the two paediatric sleep physicians who scored each participant's PSG. Inter-rater agreement is reported as $95 \%$ limits of agreement (LOA).
Table 3 Respiratory admissions

\begin{tabular}{lllllll}
\hline & & \multicolumn{2}{l}{$\begin{array}{l}\text { 2 years prior to } \\
\text { nusinersen treatment }\end{array}$} & & \multicolumn{2}{l}{$\begin{array}{l}\text { 1 year of nusinersen } \\
\text { treatment }\end{array}$} \\
\cline { 3 - 4 } Patient & SMA type & $\mathbf{n}$ & Days & & $\mathbf{n}$ & Days \\
\hline A & 1 & 6 & 123 & 4 & 38 \\
B & 1 & 1 & 10 & 3 & 66 \\
C & 1 & $\begin{array}{l}\text { Newly diagnosed (thus not } \\
\text { available) }\end{array}$ & 1 & 12 \\
D & 1 & $\begin{array}{l}\text { Newly diagnosed (thus not } \\
\text { available) }\end{array}$ & 39 \\
\hline
\end{tabular}

n, number of admissions; SMA, spinal muscular atrophy.

For all analyses, statistical significance was determined at the 0.05 level. All analyses were conducted using Stata/SE V.16.1 (StataCorp LLC, College Station, Texas, USA).

\section{RESULTS}

During the study period, QCH had 30 patients start nusinersen. Twenty-eight patients were enrolled with SMA type $1(n=7)$, type $2(n=12)$ and type $3(n=9)$. Two siblings with SMA type 2 were not approached due to severe social disharmony. Follow-up data at 12 months were available for 27/28 patients: one participant with SMA type 1 died shortly after the start of nusinersen, her parents had declined use of NIV and opted for palliative comfort care but continued nusinersen. She was excluded from analyses as no follow-up PSG or PFT was obtained. One patient with SMA type 3 underwent scoliosis surgery shortly after the start of the study and was excluded from further statistical analysis due to the potential effects of spinal surgery on lung function (26/28 remaining for statistical analysis).

\section{Baseline characteristics}

Baseline clinical characteristics are summarised in table 2. Participants who used NIV did so for sleep only. No patient required awake ventilatory support or tracheostomy. NIV use was greater in SMA type $2(66.7 \%)$ than type $1(28.6 \%)$ or type $3(11.1 \%)$ at baseline.

\section{Changes in clinical characteristics}

Changes in admission rates and length of admissions of individuals following treatment initiation are summarised in table 3. Over the course of the study, four children with SMA type 1 had respiratoryrelated hospitalisations, all needing paediatric intensive care unit

Table 2 Baseline characteristics at the start of nusinersen

\begin{tabular}{|c|c|c|c|c|}
\hline & $\begin{array}{l}\text { SMA type } 1 \\
\mathrm{n}=7\end{array}$ & $\begin{array}{l}\text { SMA type } 2 \\
\mathrm{n}=12\end{array}$ & $\begin{array}{l}\text { SMA type } 3 \\
\mathrm{n}=9\end{array}$ & $\begin{array}{l}\text { All SMA types } \\
n=28\end{array}$ \\
\hline Age in years at study initiation: median (range) & $0.42(0.08-6.00)$ & $11.04(4.42-18.58)$ & $9.08(2.75-15.00)$ & $8.71(0.08-18.58)$ \\
\hline Sex-male, n (\%) & $1(14.3)$ & $7(58.3)$ & $7(77.8)$ & $15(53.6)$ \\
\hline \multicolumn{5}{|l|}{ Survival motor neuron 2 copy number } \\
\hline 2 & 4 & 0 & 0 & 4 \\
\hline 3 & 3 & 12 & 8 & 23 \\
\hline 4 & 0 & 0 & 1 & 1 \\
\hline $\begin{array}{l}\text { Age in years at diagnosis: } \\
\text { median (range) }\end{array}$ & $0.42(0.08-1.50)$ & $1.1(0.70-1.80)$ & $2.46(1.5-12.67)$ & $1.17(0.10-12.70)$ \\
\hline Age in years at first nusinersen dose: median (range) & $0.42(0.17-5.00)$ & $9.70(3.60-18.80)$ & $7.50(0.41-15.10)$ & $7.0(0.20-18.80)$ \\
\hline NIV use at the start of study: $n(\%)$ & $2(28.6)$ & $8(66.7)$ & $1(11.1)$ & $11.0(39.3)$ \\
\hline Previous spinal instrumentation: $\mathrm{n}(\%)$ & $0(0.0)$ & $5(41.7)$ & $0(0.0)$ & $5(17.9)$ \\
\hline
\end{tabular}

NIV, non-invasive ventilation; SMA, spinal muscular atrophy. 
Table 4 Annual rate of decline in FVC Z-score percent predicted FVC 2 years prior to the start of nusinersen compared with the first year of treatment

\begin{tabular}{|c|c|c|c|c|c|c|}
\hline & \multicolumn{6}{|c|}{ Rate of decline in FVC Z-score (mean; $95 \% \mathrm{CI}$ ) per annum } \\
\hline & Prior to treatment & $P$ value & Post treatment & $P$ value & $\begin{array}{l}\text { Difference between } \\
\text { pretreatment and post- } \\
\text { treatment rate of decline }\end{array}$ & $P$ value \\
\hline $\begin{array}{l}\text { Total group } \\
(n=20)\end{array}$ & $-0.58(-0.75$ to -0.41$)$ & $<0.001$ & $-0.25(-0.46$ to -0.03$)$ & 0.02 & $0.33(0.02$ to 0.66$)$ & 0.04 \\
\hline $\begin{array}{l}\text { SMA type } 2 \\
(n=12)\end{array}$ & $-0.61(-0.77$ to -0.44$)$ & $<0.001$ & $-0.08(-0.32$ to 0.15$)$ & 0.48 & 0.52 (0.19 to 0.86$)$ & 0.002 \\
\hline \multirow{3}{*}{$\begin{array}{l}\text { SMA type } 3 \\
(\mathrm{n}=8)\end{array}$} & $-0.61(-1.09$ to -0.12$)$ & 0.01 & $-0.50(-0.91$ to -0.09$)$ & 0.02 & $0.11(-0.63$ to 0.85$)$ & 0.77 \\
\hline & \multicolumn{6}{|c|}{ Rate of decline in percent predicted FVC (mean; $95 \% \mathrm{CI}$ ) per annum } \\
\hline & 2 years prior to treatment & $P$ value & $\begin{array}{l}\text { During first year of } \\
\text { treatment }\end{array}$ & $P$ value & $\begin{array}{l}\text { Difference between } \\
\text { pretreatment and post- } \\
\text { treatment rate of decline }\end{array}$ & $P$ value \\
\hline $\begin{array}{l}\text { Total group } \\
(n=20)\end{array}$ & $-5.94(-7.74$ to -4.14$)$ & $<0.001$ & $-2.56(-4.82$ to -0.30$)$ & 0.03 & $3.38(-0.02$ to 6.78$)$ & 0.05 \\
\hline $\begin{array}{l}\text { SMA type } 2 \\
(n=12)\end{array}$ & $-5.86(-7.60$ to -4.11$)$ & $<0.001$ & $-1.03(-3.55$ to 1.50$)$ & 0.42 & $4.83(1.20$ to 8.47$)$ & 0.009 \\
\hline $\begin{array}{l}\text { SMA type } 3 \\
(n=8)\end{array}$ & $-7.69(-12.71$ to -2.67$)$ & 0.003 & $-4.75(-9.01$ to -0.49$)$ & 0.03 & $2.94(-4.70$ to 10.59$)$ & 0.45 \\
\hline
\end{tabular}

SMA, spinal muscular atrophy.

(PICU) and continuous NIV support for either viral pneumonitis or presumed aspiration pneumonia. There were no respiratory-related admissions for children with SMA type 2 or type 3.

One participant with SMA type 2 and four participants with SMA type 1 started NIV during study period (nocturnal only but $>6$ hours over 24 hours). Of four SMA type 1 patients, one started on NIV for recurrent admissions to PICU for respiratory infections requiring continuous NIV support during admissions; others were started on NIV for SDB confirmed on baseline PSG.

\section{Rate of lung function decline}

The combined rate of annual decline in FVC z-score in the 2 years prior to the start of nusinersen was -0.58 (95\% CI -0.75 to $-0.41)$ compared with -0.25 (95\% CI -0.46 to -0.03$)$ in the year post initiation, with a significantly slower rate of annual decline of 0.33 (95\% CI 0.02 to 0.66 ); $p=0.04$ (see table 4). When analysed by SMA type, rates of decline were similar for types 2 and 3 prior to nusinersen initiation, but post initiation, the decreased in the rate of decline was particularly marked in children with SMA type 2. A similar finding was observed for percent predicted FVC. Rates of decline for Osc, MIP, MEP and SNIP variables during first year of treatment only (due to limited pre-study data) are listed in online supplemental table 1 .

\section{Lung function}

Although all respiratory tests were attempted to be collected from each patient, given the extent of testing, some tests were not obtained due to patient cooperation or were excluded as they did not represent technically acceptable tests. Only children with SMA types 2 and 3 performed lung function. Summary statistics for lung function tests at the start of nusinersen (baseline) and after 12-month treatment are displayed in table 5. No clinically important changes in lung function were observed over this period.

\section{Polysomnography}

There was agreement in the scoring between the two sleep physicians (total AHI (95\% LOA 0-1)). Total and REM stage AHI and central apnoea index improved at both a clinically and statistically significant level in SMA type 1 (figure 1). The median AHI reduced from 4.4 (IQR 0.8-8.3) at nusinersen initiation to 3.4 (IQR 1.3-6.3) after 1 year $(p=0.04)$. Total and REM stage minimum recorded oxygen saturations made a clinically meaningful improvement both for the total cohort and children with type 1 SMA. Changes in sleep study variables are summarised in online supplemental table 1. There was no association observed between AHI and age $(0.26$ $(-0.19,0.71))(\mathrm{p}=0.25)$.

\section{Peripheral Muscle function}

Peripheral muscle function test scores are listed in table 6. All SMA type $1 \%$ and $75 \%$ of SMA types 2 and 3 showed an improvement in peripheral muscle function greater than predefined response threshold.

\section{Association between respiratory and PSG assessments and muscle response to nusinersen}

When participants were grouped according to whether or not they were peripheral muscle function responders, children who were responders had a greater reduction in total AHI and FVC z-score tended to improve. For the five participants considered as nonresponders, AHI total tended to reduced in the year post nusinersen initiation, while FVC z-score increased (online supplemental table 2).

\section{DISCUSSION}

This study reports changes in lung function and PSG parameters in the first year of nusinersen treatment. These preliminary 'real world' findings show that nusinersen appears to stabilise respiratory function and improve SDB in children with SMA. 
Table 5 Respiratory function tests at the start of nusinersen (baseline) compared with 1 year: within-participant difference analysed by MannWhitney U test

\begin{tabular}{|c|c|c|c|c|c|c|c|c|c|}
\hline \multirow[b]{3}{*}{ Respiratory variable } & \multicolumn{9}{|l|}{ SMA type } \\
\hline & \multicolumn{3}{|l|}{ SMA type $2(n=12)$} & \multicolumn{3}{|l|}{ SMA type $3(n=8)$} & \multicolumn{3}{|c|}{ Combined SMA types 2 and $3(n=20)$} \\
\hline & Baseline & 1 year & $P$ value & Baseline & 1 year & $P$ value & Baseline & 1 year & $P$ value \\
\hline $\begin{array}{l}\text { FVC Z-score } \\
\text { Mean (SD) }\end{array}$ & $\begin{array}{l}n=12 \\
-4.88(2.22)\end{array}$ & $\begin{array}{l}n=11 \\
-4.85(2.30)\end{array}$ & 0.85 & $\begin{array}{l}n=7 \\
-0.16(1.40)\end{array}$ & $\begin{array}{l}n=8 \\
-0.44(1.53)\end{array}$ & 0.82 & $\begin{array}{l}n=19 \\
-3.15(3.03)\end{array}$ & $\begin{array}{l}n=19 \\
-2.99(2.98)\end{array}$ & 0.99 \\
\hline $\begin{array}{l}\text { FVC \% predicted Mean } \\
\text { (SD) }\end{array}$ & $\begin{array}{l}n=12 \\
44.58(23.22)\end{array}$ & $\begin{array}{l}n=11 \\
44.82(24.09)\end{array}$ & 0.88 & $\begin{array}{l}n=7 \\
98.14(17.58)\end{array}$ & $\begin{array}{l}\mathrm{n}=8 \\
94.88(19.48)\end{array}$ & 0.73 & $\begin{array}{l}\mathrm{n}=19 \\
64.32(33.72)\end{array}$ & $\begin{array}{l}n=19 \\
65.89(33.39)\end{array}$ & 1.00 \\
\hline $\begin{array}{l}\text { Rrs8 Z-score } \\
\text { Mean (SD) }\end{array}$ & $\begin{array}{l}n=9 \\
1.44(1.46)\end{array}$ & $\begin{array}{l}n=5 \\
1.52(1.4)\end{array}$ & 0.95 & $\begin{array}{l}\mathrm{n}=8 \\
0.37(0.92)\end{array}$ & $\begin{array}{l}n=6 \\
0.02(1.83)\end{array}$ & 0.19 & $\begin{array}{l}n=17 \\
0.93(1.31)\end{array}$ & $\begin{array}{l}\mathrm{n}=11 \\
0.70(1.89)\end{array}$ & 0.44 \\
\hline $\begin{array}{l}\text { Xrs8 Z-score } \\
\text { Mean (SD) }\end{array}$ & $\begin{array}{l}n=9 \\
1.04(1.22)\end{array}$ & $\begin{array}{l}n=5 \\
1.38(2.47)\end{array}$ & 0.95 & $\begin{array}{l}\mathrm{n}=8 \\
0.76(1.40)\end{array}$ & $\begin{array}{l}\mathrm{n}=6 \\
0.33(1.59)\end{array}$ & 0.27 & $\begin{array}{l}n=17 \\
0.91(1.27)\end{array}$ & $\begin{array}{l}n=11 \\
0.80(2.00)\end{array}$ & 0.40 \\
\hline $\begin{array}{l}\text { LCl } \\
\text { Median (25\%-75\%) }\end{array}$ & $\begin{array}{l}n=9 \\
8.13(7.82-10.09)\end{array}$ & $\begin{array}{l}n=7 \\
9.31(7.37-10.21)\end{array}$ & 0.67 & $\begin{array}{l}n=7 \\
7.82(7.09-8.76)\end{array}$ & $\begin{array}{l}n=6 \\
6.93(6.32-7.42)\end{array}$ & 0.06 & $\begin{array}{l}n=16 \\
8.10(7.63-10.00)\end{array}$ & $\begin{array}{l}n=13 \\
7.42(7.11-9.31)\end{array}$ & 0.14 \\
\hline $\begin{array}{l}\text { FRC (L) } \\
\text { Median }(25 \%-75 \%)\end{array}$ & $\begin{array}{l}\mathrm{n}=9 \\
0.9(0.8-1.1)\end{array}$ & $\begin{array}{l}\mathrm{n}=5 \\
1.0(0.9-1.1)\end{array}$ & 0.95 & $\begin{array}{l}n=8 \\
1.1(0.8-1.6)\end{array}$ & $\begin{array}{l}n=6 \\
1.4(1.1-2.2)\end{array}$ & 0.89 & $\begin{array}{l}\mathrm{n}=16 \\
1.0(0.8-1.1)\end{array}$ & $\begin{array}{l}n=13 \\
1.1(0.9-1.1)\end{array}$ & 0.90 \\
\hline $\begin{array}{l}\text { PCF (L/min) } \\
\text { Median (25\%-75\%) }\end{array}$ & $\begin{array}{l}n=8 \\
156.9(116.7-216.3)\end{array}$ & $\begin{array}{l}n=8 \\
128.7(111.9-177.9)\end{array}$ & 0.43 & $\begin{array}{l}n=5 \\
242.4(237.0-322.3)\end{array}$ & $\begin{array}{l}n=5 \\
242.4(237.0-353.4)\end{array}$ & 0.17 & $\begin{array}{l}n=13 \\
215.4(147.6-242.4)\end{array}$ & $\begin{array}{l}n=13 \\
208.8(119.4-254.4)\end{array}$ & 1.00 \\
\hline $\begin{array}{l}\text { SNIP }\left(\mathrm{cm} \mathrm{H}_{2} \mathrm{O}\right) \\
\text { Median }(\mathrm{SD})\end{array}$ & $\begin{array}{l}n=9 \\
41.0(27.0-73.0)\end{array}$ & $\begin{array}{l}n=7 \\
44.0(28.0-73.0)\end{array}$ & 0.74 & $\begin{array}{l}n=5 \\
76.5(57.0-83.0)\end{array}$ & $\begin{array}{l}n=5 \\
83.0(68.0-92.0)\end{array}$ & 0.61 & $\begin{array}{l}n=14 \\
57.0(28.0-73.0)\end{array}$ & $\begin{array}{l}n=12 \\
68.0(44.0-86.0)\end{array}$ & 0.51 \\
\hline $\begin{array}{l}\text { MIP Z-score } \\
\text { Mean (SD) }\end{array}$ & $\begin{array}{l}n=8 \\
-1.09(1.23)\end{array}$ & $\begin{array}{l}n=8 \\
-1.24(1.62)\end{array}$ & 0.49 & $\begin{array}{l}n=5 \\
0.03(0.75)\end{array}$ & $\begin{array}{l}n=5 \\
0.04(0.96)\end{array}$ & 0.92 & $\begin{array}{l}n=13 \\
-0.66(1.18)\end{array}$ & $\begin{array}{l}n=13 \\
-0.758(1.51)\end{array}$ & 0.64 \\
\hline $\begin{array}{l}\text { MEP Z-score } \\
\text { Mean (SD) }\end{array}$ & $\begin{array}{l}n=8 \\
-2.61(1.12)\end{array}$ & $\begin{array}{l}n=8 \\
-3.16(0.38)\end{array}$ & 0.49 & $\begin{array}{l}n=5 \\
-1.34(0.91)\end{array}$ & $\begin{array}{l}n=5 \\
-0.93(1.21)\end{array}$ & 0.25 & $\begin{array}{l}n=13 \\
-2.12(1.19)\end{array}$ & $\begin{array}{l}n=13 \\
-2.30(1.36)\end{array}$ & 0.78 \\
\hline
\end{tabular}

FRC, functional residual capacity; LCI, Lung Clearance Index; MEP, mean expiratory pressure; MIP, mean inspiratory pressure; PCF, peak cough flow; Rrs8, respiratory resistance at 8 Hz; SMA, spinal muscular atrophy; Xrs8, respiratory reactance at 8

Decline in FVC prior to nusinersen initiation was reduced during the first year of treatment, particularly in type 2 SMA; however, these results must be treated cautiously due to the lack of precision (and consequently wide 95\% CI) for some subanalyses. Comparison between retrospective spirometry data to prospective results was required due to lack of good quality published reference data and significant disease variability between individuals. Comparison was able to be made for the same patient in two different conditions (no treatment and nusinersen).

Previous spirometry literature in SMA types 2 and 3 is primarily reported as cross-sectional statistics. In earlier reports, SMA type 2 and 3 patients were pooled and reported retrospectively. Rates of FVC decline varied between $-1.1 \%$ predicted per annum (pa) in children and adults ${ }^{20}$ and $-3.1 \%$ at 2 years and $-2.95 \%$ at 3 years. ${ }^{21} 22$ Children and young adults with SMA type 2 have a steeper decline (FVC of $-3.3 \%$ to $-9.8 \%$ pa) than SMA type $3(-1.8 \%$ to $-4.2 \% \mathrm{pa}){ }^{23}{ }^{24} \mathrm{In}$ addition to SMA type variation, there is a difference in median percent predicted FVC based on the continuum of patient phenotype (SMA subtypes), with poorest values noted in non-sitter SMA type 2 and higher values in ambulant SMA type $3 .^{25}$ Recently, the effect of age on lung function decline has been noted. FVC \% predicted decline is most pronounced at younger ages, followed by a slower rate of decline or even stable course during adulthood in SMA types $2 \mathrm{a}$ and $3 \mathrm{a}$, whereas FVC remained relatively stable in type $3 b$ throughout life. ${ }^{232426}$ Annual decline of FVC \% predicted has been reported between -0.23 and

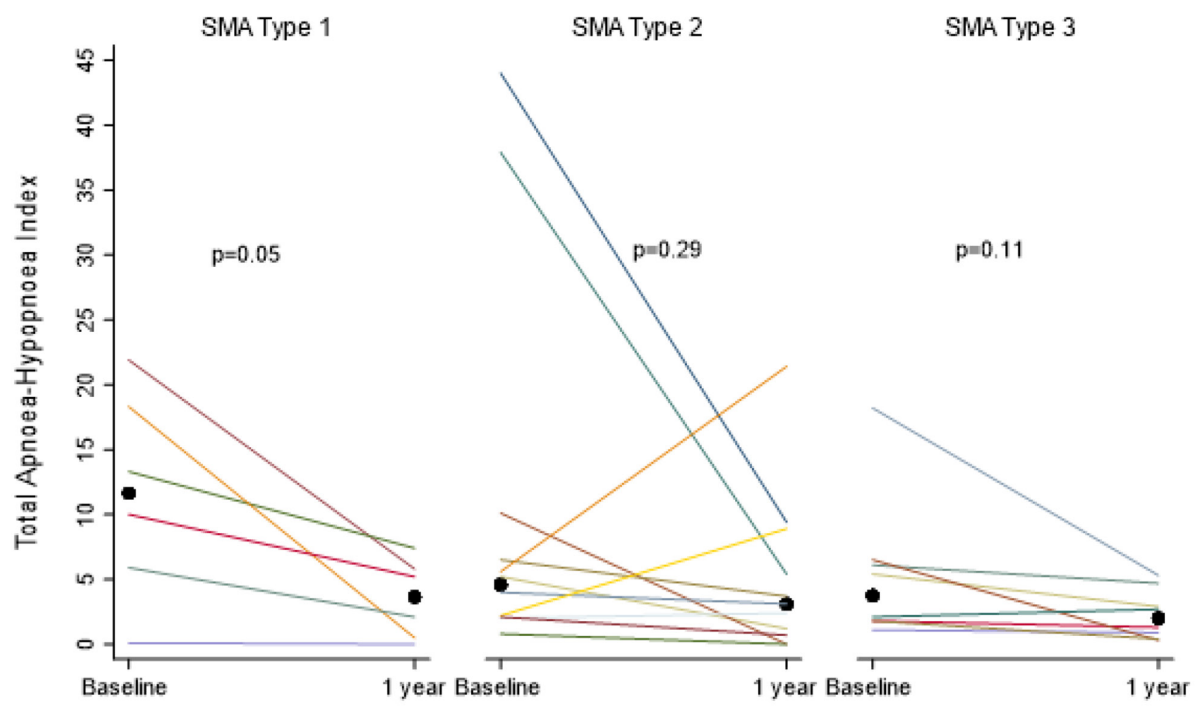

Figure 1 Apnoea-Hypopnoea Index (AHI) total at baseline and 1 year for spinal muscular atrophy (SMA) types 1, 2 and 3. 
$-1.32 \%$ from SMA type $3 b$ to $2 a .{ }^{26}$ Our pretreatment FVC decline is similar to that reported by Khirani et $_{\text {al. }} .^{23}$

The mechanisms for lung function response differences in SMA type 2 compared with type 3 include the following: (1) participants with type 3 had normal range at initiation, thus have less margin for improvement; (2) nusinersen may take longer to manifest in type 3 (as less severe disease); or (3) nusinersen response is less in type 3, although a biologically plausible explanation is elusive. Tendency to slower peripheral muscle function response in type 3 is reported, giving plausibility to the rationale for a lesser response in type 3 over the first 12 months of treatment. ${ }^{82}$

The introduction of nusinersen was associated with a significant reduction in the rate of lung function decline. Nusinersen may have halted the expected progression of disease. Natural history would suggest ongoing decline. A lack of improvement in baseline lung function could be due to the chronic changes occurring in neuromuscular diseases. Reduction in chest wall muscle contraction leads to fibrotic, shortened and stiffened muscles, while reduced movement of chest wall results in articular contractures. Neither effect may be reversible. ${ }^{27}$

Our results showed a treatment-related fall in resistance with trends towards improvement in reactance and increase in FRC. Again, limited published literature using Osc in SMA exists with none on rates of decline. ${ }^{1928}$ Current study group mean Osc z-scores at baseline suggest reduced lung volumes during tidal breathing, fitting with respiratory muscle weakness expected in SMA. Prior Osc studies in SMA showed that FRC reduces over time. ${ }^{23}$ Our findings suggests increased lung volume during tidal breathing from improvement in respiratory muscle strength. SMA type 2 tended to have higher LCI values (more abnormal) than SMA type 3, similar to previous report. ${ }^{28}$

SMA type 2 has lower baseline results for PCF, SNIP, MIP and MEP (MIP lower than MEP) compared with SMA type $3^{19} 2325$ due to weakness of intercostal muscles \pm diaphragmatic muscles. ${ }^{29} 30$ Although mean annual SNIP percent predicted decline is similar between type 2 and type 3 (5.4\% vs 6.4\% respectively), the decline is later in type $3 .^{23}$ Lower values in SMA type 2 for PCF, SNIP, MIP and MEP were shown in our population with tendency for improvement with treatment in SMA type 3 for all values and SNIP in type 2. Results may be influenced by the imprecision due to the small sample (not all children were able to perform techniques). Also variability between tests is expected due to the large variation in the spectrum of peripheral muscle weakness seen in SMA and possibly differences in respiratory muscle function profiles. ${ }^{30}$

This is the first study to show an improvement in SDB with nusinersen treatment. All SMA types have central and mixed SDB. ${ }^{1431} 32$ Our study showed improvements in central apnoea index, total $\mathrm{AHI}$ and oxygen saturation. Reduction in total AHI was largely attributed to reduction in REM stage AHI/central indices and not surprising since respiratory pump failure is pronounced in REM sleep. ${ }^{33} \mathrm{AHI}$ total reduction was greater in type 1 possibly due to known age-related reduction in AHI. ${ }^{34}{ }^{35}$ It may also be that type 2 or type 3 SMA eitherdid not have severe SDB at baseline so AHI reduction was less dramatic or as they had prolonged time between diagnosis and first dose of nusinersen, consequently, had reduced efficacy of respiratory muscle response to nusinersen. ${ }^{4}$ Increased peripheral muscle response is shown with shorter disease duration. ${ }^{5}$ No participants had hypoventilation ${ }^{36}$ on PSG. Indications for NIV initiation were recurrent chest infections needing PICU admissions for continuous NIV or SDB, and thus, our centre is likely starting NIV early prior to signs of hypoventilation and raised $\mathrm{TcCO}_{2}$.

One participant death occurred after the start of nusinersen. The child's family elected against NIV, which likely impacted mortality risk. All other children with SMA type 1 started NIV following identification of SDB on initial sleep study or for recurrent chest infections requiring PICU admissions. This improved their survival when compared with historical mortality data ${ }^{37}$ but in keeping with improved survival noted in ENDEAR trial and real-world Italian experience. $^{538}$

We were unable to assess whether peripheral muscle response was associated with a lung function or PSG change as a large proportion of children fit peripheral muscle response definition, making subgroup analysis difficult. A large group of responders suggested that the definition adopted from the ENDEAR/CHERISH trials (validated testing but subjective clinically meaningful change) ${ }^{45}$ may not reflect objective changes seen with FVC and AHI measurements; or peripheral muscle function tests may not be sensitive enough to detect differences in respiratory muscle function over a short period of time. This may be especially true in slowly progressive subtypes, which have shown different trajectories based on ambulation and at different age groups. ${ }^{21} 2239$ Electrophysiological outcome measures (compound muscle action potential) may be more accurate and improve with nusinersen. ${ }^{45}$ However, electrodiagnostic studies require considerable evaluator skill and participant discomfort, which is compounded by the young population of interest who may not cooperate. The present study attempted to use age-appropriate and disease relevant outcome measures ${ }^{15}$ used in previous studies. The variety of scales used in the present study also made detecting changes within same SMA type difficult, but scales needed to be appropriate to child's age and level of function. No single scale spans across the entire paediatric age range.

The primary limitation of this study was the small sample size, due largely to the rarity of SMA. As a consequence, the effect estimates are often imprecise, and we have limited power to detect statistical differences for some subtype analyses. Although participants are a representative sample of children with SMA in Queensland, Australia, our findings may not generalise to patients elsewhere. Infant lung function was not measured, so lung function measurements were limited to older, cooperative children. At present, only one study has assessed the effect of nusinersen on infant lung function. ${ }^{40}$ Trials in nusinersen have shown greater peripheral muscle function response in those treated early with shorter disease

Table 6 Muscle function scores

\begin{tabular}{|c|c|c|c|c|c|c|}
\hline & \multicolumn{2}{|l|}{ SMA type $1(n=6)$} & \multicolumn{3}{|c|}{ SMA type $2(n=12)$} & \multirow{2}{*}{$\begin{array}{l}\text { SMA type } 3(n=8) \\
\text { HMFSE }\end{array}$} \\
\hline & CHOP-INTEND & RULM & CHOP-INTEND & RULM & HMFSE & \\
\hline Baseline $n$, median (25\%-75\%) & $\begin{array}{l}5, \\
27.5(24.0-36.0)\end{array}$ & $\begin{array}{l}1, \\
9.0\end{array}$ & $\begin{array}{l}1, \\
32.0\end{array}$ & $\begin{array}{l}9, \\
8.5(6.0-14.5)\end{array}$ & $\begin{array}{l}3, \\
32.0(29.0-45.0)\end{array}$ & $\begin{array}{l}8, \\
45.0(31.0-47.0)\end{array}$ \\
\hline 12 months $n$, median $(25 \%-75 \%)$ & $\begin{array}{l}5, \\
44.0(38.5-55.5)\end{array}$ & $\begin{array}{l}1, \\
10.0\end{array}$ & $\begin{array}{l}1, \\
41.0\end{array}$ & $\begin{array}{l}9, \\
9.0(7.0-13.0)\end{array}$ & $\begin{array}{l}3, \\
34.0(33.0-51.0)\end{array}$ & $\begin{array}{l}8, \\
49.0(40.0-52.0)\end{array}$ \\
\hline Peripheral muscle function responders, $\mathrm{n}$ & 5 & 1 & 1 & 7 & 2 & 6 \\
\hline
\end{tabular}

CHOP INTEND, Children's Hospital of Philadelphia Infant Test of Neuromuscular Disorders; HFMSE, Hammersmith Functional Motor Scale—Expanded; RULM, Revised Upper Limb Module. 
duration. ${ }^{5}$ This may also be true for respiratory muscle function. However, as nusinersen was only widely introduced in Australia in 2018, most Queensland children with SMA type 2 and type 3 had a delay of 8-9years before treatment. Retrospective collection of lung function data prior to nusinersen initiation is not ideal. However, as nusinersen is available and offered to all children in most countries, all future trials will likely involve children receiving a diseasemodifying medication, so it is unethical to perform studies with a placebo group. Historical controls or retrospective data will need to be used. Lastly, the effect of SMN2 copy number was not assessed due to small numbers.

\section{CONCLUSION}

First year of nusinersen treatment led to reduction in lung function decline as measured by FVC z-scores and improvement in PSG (total AHI and central indices). Other lung function parameters remained largely stable. Larger, multicentre studies are needed to further characterise the effects of nusinersen on respiratory muscle function, especially in SMA type 3 where effects may be smaller or slower to respond.

Correction notice This article has been corrected since it was published Online First. Figure 1 has been corrected.

Acknowledgements The authors would like to thank the patients and their families and the Neuromuscular Department at the Queensland Children's Hospital, Brisbane, Australia.

Contributors $A C$ and $L G$ planned the study. SD and NT performed lung function and peripheral muscle testing, respectively. AC, NB and RSW analysed the results. AC wrote the manuscript. LG and PDS contributed to writing the manuscript.

Funding This study was supported by Biogen Global as an investigator-initiated project.

\section{Competing interests None declared.}

Patient consent for publication Not required.

Ethics approval The study was approved by Children's Health Queensland Ethical Committee (HREC/18/QRCH/90).

Provenance and peer review Not commissioned; externally peer reviewed.

Data availability statement All data relevant to the study are included in the article or uploaded as supplementary information. Additional individual patient data are available in deidentified format on reasonable request.

ORCID iDs

Peter D Sly http://orcid.org/0000-0001-6305-2201

Leanne M Gauld http://orcid.org/0000-0003-0819-894X

\section{REFERENCES}

1 Lunn MR, Wang CH. Spinal muscular atrophy. Lancet 2008:371:2120-33.

2 Ottesen EW. ISS-N1 makes the first FDA-approved drug for spinal muscular atrophy. Trans/ Neurosci 2017:8:1-6.

3 Munsat TL, Davies KE. International SMA Consortium meeting. (26-28 June 1992, Bonn, Germany). Neuromuscul Disord 1992;2:423-8.

4 Mercuri E, Darras BT, Chiriboga CA, et al. Nusinersen versus sham control in LaterOnset spinal muscular atrophy. N Eng/ J Med Overseas Ed 2018;378:625-35.

5 Finkel RS, Mercuri E, Darras BT, et al. Nusinersen versus sham control in infantileonset spinal muscular atrophy. N Eng/ J Med 2017;377:1723-32.

6 Mercuri E, Darras BT, Chiriboga CA, et al. Nusinersen versus sham control in LaterOnset spinal muscular atrophy. N Eng/ J Med 2018;378:625-35.

7 Sansone VA, Pirola A, Albamonte E, et al. Respiratory Needs in Patients with Type 1 Spinal Muscular Atrophy Treated with Nusinersen. J Pediatr 2020;219:223-8.

8 Darras BT, Chiriboga CA, lannaccone ST, et al. Nusinersen in later-onset spinal muscular atrophy: long-term results from the phase $1 / 2$ studies. Neurology 2019;92:e2492-506

9 Zerres K, Rudnik-Schöneborn S. Natural history in proximal spinal muscular atrophy. clinical analysis of 445 patients and suggestions for a modification of existing classifications. Arch Neurol 1995:52:518-23.
10 Samaha FJ, Buncher CR, Russman BS, et al. Pulmonary function in spinal muscular atrophy. J Child Neurol 1994;9:326-9.

11 Mercuri E, Bertini E, lannaccone ST. Childhood spinal muscular atrophy: controversies and challenges. Lancet Neurol 2012;11:443-52.

12 Graham BL, Steenbruggen I, Miller MR, et al. Standardization of spirometry 2019 update. An official American thoracic Society and European respiratory Society technical statement. Am J Respir Crit Care Med 2019;200:e70-88.

13 Berry RB QS, Abreu AR, Bibbs ML, et al. The American Academy of sleep medicine manual for the scoring of sleep and associated events: rules, terminology and technical specifications. Darien, Illinois: American Academy of Sleep Medicine, 2020.

14 Chacko A, Sly PD, Gauld L. Polysomnography findings in pediatric spinal muscular atrophy types 1-3. Sleep Med 2020;68:124-30.

15 Finkel R, Bertini E, Muntoni F, et al. 209th ENMC International workshop: outcome measures and clinical trial readiness in spinal muscular atrophy 7-9 November 2014, Heemskerk, the Netherlands. Neuromuscul Disord 2015;25:593-602.

16 Glanzman AM, McDermott MP, Montes J, et al. Validation of the children's Hospital of Philadelphia infant test of neuromuscular disorders (CHOP INTEND). Pediatr Phys Ther 2011;23:322-6.

17 O'Hagen JM, Glanzman AM, McDermott MP, et al. An expanded version of the Hammersmith functional motor scale for SMA II and III patients. Neuromuscul Disord 2007:17:693-7.

18 Mazzone ES, Mayhew A, Montes J, et al. Revised upper limb module for spinal muscular atrophy: development of a new module. Muscle Nerve 2017;55:869-74.

19 Gauld LM, Keeling LA, Shackleton CE, et al. Forced oscillation technique in spinal muscular atrophy. Chest 2014;146:795-803.

20 Steffensen B, Hyde S, Lyager S, et al. Validity of the EK scale: a functional assessment of non-ambulatory individuals with Duchenne muscular dystrophy or spinal muscular atrophy. Physiother Res Int 2001:6:119-34.

21 Kaufmann P, McDermott MP, Darras BT, et al. Observational study of spinal muscular atrophy type 2 and 3: functional outcomes over 1 year. Arch Neurol 2011;68:779-86.

22 Kaufmann P, McDermott MP, Darras BT, et al. Prospective cohort study of spinal muscular atrophy types 2 and 3. Neurology 2012;79:1889-97.

23 Khirani S, Colella M, Caldarelli V, et al. Longitudinal course of lung function and respiratory muscle strength in spinal muscular atrophy type 2 and 3. Eur J Paediatr Neurol 2013:17:552-60.

24 Trucco F, Ridout D, Finkel R, et al. P.223Respiratory function in SMA type 2 and non-ambulant SMA type 3, longitudinal data from the International SMA Consortium (iSMAc). Neuromuscular Disorders 2019;29:S131-2.

25 Chabanon A, Seferian AM, Daron A, et al. Prospective and longitudinal natural history study of patients with type 2 and 3 spinal muscular atrophy: baseline data NatHisSMA study. PLoS One 2018;13:e0201004.

26 Wijngaarde CA, Veldhoen ES, van Eijk RPA, et al. Natural history of lung function in spinal muscular atrophy. Orphanet J Rare Dis 2020;15:88.

27 Estenne M, Heilporn A, Delhez L, et al. Chest wall stiffness in patients with chronic respiratory muscle weakness. Am Rev Respir Dis 1983;128:1002-7.

28 Kapur N, Deegan S, Parakh A, et al. Relationship between respiratory function and need for NIV in childhood SMA. Pediatr Pulmonol 2019;54:1774-80.

29 LoMauro A, Romei M, Priori R, et al. Alterations of thoraco-abdominal volumes and asynchronies in patients with spinal muscle atrophy type III. Respir Physiol Neurobiol 2014;197:1-8.

30 Khirani S, Amaddeo A, Fauroux B. Cough, sniff and maximal static pressure patterns in spinal muscular atrophy. Respir Physiol Neurobiol 2020;271:103308.

31 Mellies U, Dohna-Schwake C, Stehling F, et al. Sleep disordered breathing in spinal muscular atrophy. Neuromuscul Disord 2004;14:797-803.

32 Pera MC, Romeo DM, Graziano A, et al. Sleep disorders in spinal muscular atrophy. Sleep Med 2017;30:160-3.

33 Culebras A. Sleep disorders and neuromuscular disease. Semin Neurol 2005:25:33-8.

34 Brockmann PE, Poets A, Poets CF. Reference values for respiratory events in overnight polygraphy from infants aged 1 and 3months. Sleep Med 2013;14:1323-7.

35 Uliel S, Tauman R, Greenfeld M, et al. Normal polysomnographic respiratory values in children and adolescents. Chest 2004;125:872-8.

36 Birnkrant DJ, Bushby K, Bann CM, et al. Diagnosis and management of Duchenne muscular dystrophy, part 2: respiratory, cardiac, bone health, and orthopaedic management. Lancet Neurol 2018;17:347-61.

37 Darras BT, De Vivo DC. Precious SMA natural history data: a benchmark to measure future treatment successes. Neurology 2018;91:337-9.

38 Sansone VA, Racca F, Ottonello G, et al. 1st Italian SMA family association consensus meeting: management and recommendations for respiratory involvement in spinal muscular atrophy (SMA) types I-III, Rome, Italy, 30-31 January 2015. Neuromuscul Disord 2015;25:979-89.

39 Mercuri E, Finkel R, Montes J, et al. Patterns of disease progression in type 2 and 3 SMA: implications for clinical trials. Neuromuscul Disord 2016;26:126-31.

40 LoMauro A, Mastella C, Alberti K, et al. Effect of nusinersen on respiratory muscle function in different subtypes of type 1 spinal muscular atrophy. Am J Respir Crit Care Med 2019:200:1547-50. 